\title{
Tres generaciones del procedimiento administrativo
}

\section{Three generations of administrative procedure}

\section{JAVIER BARNES}

Resumen: El presente trabajo pretende explicar las diversas generaciones del procedimiento administrativo para así esbozar, a partir de sus virtudes y déficits, algunos de los valores y principios en juego. Entendemos por administración «imperativa» aquella que opera haciendo uso de potestades públicas y resuelve con carácter unilateral en un proceso jerárquico o en cascada, de arriba hacia abajo, mientras que la «cooperativa» se da cuando la administración no es autosuficiente y requiere de la colaboración de otras administraciones y del sector privado. El proceso no es jerárquico, sino en red. Finalmente, por «gobernanza», sea administrativa o cooperativa, se hace referencia a un nuevo estilo de gobierno, en el cual la administración goza de un particular protagonismo en la realización y ejecución de las políticas públicas. En este orden de ideas, el concepto de «procedimiento administrativo» no se detiene ya en la exclusiva idea de procedimiento como proceso decisorio, sino que también implica la obtención y el intercambio de información — para elaborar un mapa medioambiental, realizar una inspección, recabar informes y estudios científicos, por ejemplo-.

Palabras clave: Procedimiento administrativo - administración imperativa gobernanza corporativa - gobernanza administrativa

Summary: This work aims to explain the diverse generations of the administrative procedure to outline, based on their potentialities and deficits, some of the values and principles involved. «Imperative» Administration, is understood as that which operates using public powers and resolves unilaterally on a hierarchical or cascade process - from top to bottom - while the «cooperative» occurs when the administration is not self-sufficient and needs help from other administrations and the private sector, this process is not hierarchical, but in network. Finally, by governance, whether administrative or cooperative, it refers to a new style of government in which the Administration has a prominent role in the elaboration and execution of public policies. In this sequence of ideas, concept of administrative procedure is not only related with the sole idea of procedure as a decision-making process, but also involves the collection and exchange of information (for instance, to elaborate an environmental map, to make an inspection or in order to obtain reports and scientific studies).

Key words: Administrative procedure - «imperative» administration cooperative governance - administrative governance

* Es catedrático de Derecho administrativo en la Universidad de Huelva, España. Correo electrónico: javier.barnes@globallawpress.org. 
CONTENIDO: I. INTRODUCCIÓN. - I.1. EL PROCEDIMIENTO ADMINISTRATIVO EN PERSPECTIVA COMPARADA. - I.2. EL ORIGEN PROCESAL DEL PROCEDIMIENTO ADMINISTRATIVO: CUANDO LA CONQUISTA HISTÓRICA RESULTA INSUFICIENTE. - II. PROCEDIMIENTOS DE PRIMERA GENERACIÓN. - II.1. CUATRO NOTAS CARACTERÍSTICAS. - II.2. LA DISTANCIA O EL DESFASE HISTÓRICO ENTRE LA LEGISLACIÓN TRADICIONAL (PROCEDIMIENTO DE PRIMERA GENERACIÓN) Y LA REALIDAD. - III. SEGUNDA GENERACIÓN: NORMAS ADMINISTRATIVAS APROBADAS POR ADMINISTRACIÓN JERÁRQUICA. - IV. TERCERA GENERACIÓN: ACTOS, NORMAS Y POLÍTICAS PÚBLICAS ELABORADOS EN EL ENTORNO DE LAS NUEVAS FORMAS DE GOBERNANZA. - IV.1. LAS COORDENADAS DE LAS NUEVAS FORMAS DE GOBIERNO Y ADMINISTRACIÓN: LA GOBERNANZA ADMINISTRATIVA COMO PRESUPUESTO Y ENTORNO DE LOS PROCEDIMIENTOS ADMINISTRATIVOS DETERCERA GENERACIÓN. - IV.2. LA FUNCIÓN DEL PROCEDIMIENTO EN EL MARCO DE LA GOBERNANZA ADMINISTRATIVA: EL PROCEDIMIENTO COMO INSTRUMENTO DE DIRECCIÓN DE LA ADMINISTRACIÓN POR PARTE DEL PARLAMENTO, Y DE DIRECCIÓN DEL SECTOR POR PARTE DE LA ADMINISTRACIÓN. - IV.3. ALGUNAS NOTAS DE LOS PROCEDIMIENTOS DE TERCERA GENERACIÓN. - V.TRES GENERACIONES DE PROCEDIMIENTO ADMINISTRATIVO: TRES «TEORÍAS GENERALES».

\section{INTRODUCCIÓN}

\section{I.1. El procedimiento administrativo en perspectiva comparada}

La proliferación en las últimas décadas de leyes de procedimiento administrativo en extensas áreas regionales como el este de Europa, el sudeste de Asia o la América Latina constituye un fenómeno positivo, que recuerda la expansión del constitucionalismo de principios del siglo XIX, y supone, por otra parte, un evidente florecimiento del Derecho administrativo contemporáneo.

Ahora bien, el análisis comparado de una institución como el procedimiento administrativo excede en mucho del contraste y cotejo de las legislaciones nacionales y de las respectivas construcciones jurisprudenciales y doctrinales, por más que ese intercambio de experiencias — siempre en su debido contexto- pueda ser de sumo provecho, por ejemplo, para reflexionar sobre las mejores opciones sobre la sustanciación del derecho de acceso a la documentación administrativa.

Tampoco se detiene el estudio comparado en la datación histórica de las recíprocas influencias entre países o en la filiación y genealogía de las leyes y de los sistemas jurídicos, pese al interés que ello despierta por la rica información que ofrece. Por ejemplo, esa perspectiva explica, por razones de historia y cultura, la autonomía y singularidades de la gran familia de leyes iberoamericanas de procedimiento administrativo. 
Aunque la mera antigüedad no sea argumento suficiente, sí resulta ilustrativa, cuando menos, de una fuerte tradición: las primeras leyes de procedimiento se remontan a la España de $1881^{1}$ y $1889^{2}$, y las primeras no peninsulares a Cuba, Puerto Rico y Filipinas, allá por $1888^{3}$.

En realidad, la institución del procedimiento administrativo es tan poliédrica en sus funciones y morfología, y resulta tan transversal —recorre el entero Derecho administrativo-, que la comparación solo puede emprenderse por categorías de procedimiento. ¿De qué procedimiento administrativo hablamos en cada caso puesto que entre un procedimiento sancionatorio y un procedimiento de evaluación estratégica ambiental o de elaboración del planeamiento parecen existir diferencias de sustancia? Tal sería la primera interrogante a despejar. La primera cuestión que ha de resolverse, pues, reside en su identificación y ulterior clasificación.

Las categorías, clases o tipos de procedimiento, en contra de lo que ha podido pensarse durante largo tiempo, no vienen determinadas, a nuestro juicio, en razón de la materia — procedimientos para el otorgamiento de licencias en el ámbito del comercio o la vivienda, por ejemplo-, ni por el contenido o naturaleza de la resolución que ponga fin al procedimiento — acto declarativo o constitutivo, por ejemplo_- Las cosas son más complejas, pero también más interesantes. La clasificación que aquí se propone resulta más radical y profunda, puesto que se basa, en última instancia, en el modelo de administración, y en la forma de gobierno y regulación en el que aquella se inserta. Hablamos aquí de generaciones para hacer referencia a la sucesión - $-\mathrm{y}$ convivencia- de esos distintos modos de operar. Es decir, una cosa es la administración resolviendo como si de un juez se tratara (primera generación), otra es cuando ella dicta normas en modo análogo a como lo hace el legislador tradicional (segunda generación), y otra muy distinta hace referencia a cuando la administración y otros actores se sirven de elementos o principios de procedimiento en las nuevas formas de gobernanza, los cuales están marcados por la colaboración entre administraciones, tanto dentro de las propias fronteras como más allá del Estado.

Esta clasificación por generaciones permite entender mejor la institución del procedimiento dentro del propio sistema y establecer un adecuado término de comparación. No son magnitudes comparables, por

1 Real Decreto del 31 de diciembre de 1881, que aprobaba el Reglamento provisional sobre el procedimiento administrativo en las reclamaciones económico-administrativas. Se trata, en efecto, de una norma de rango infralegal.

2 Ley del 19 de octubre de 1889, la cual disponía que por cada ministerio se publique un reglamento de procedimiento administrativo para las dependencias centrales, provinciales y locales del mismo. Se trata de una ley de bases que sirve de marco y denominador común a los reglamentos que, en razón del ramo y la especialidad, habrían de dictarse seguidamente.

3 Real Decreto del 29 de septiembre de 1888, por el que se aprueba el procedimiento administrativo de la Secretaría de Ultramar y todas las dependencias administrativas de Cuba, Puerto Rico y Filipinas; y real decreto del 13 de junio de 1890 , declarado subsistente con las modificaciones que se expresan de 1890. 
ejemplo, los procedimientos administrativos sancionadores ${ }^{4}$ con los de evaluación estratégica ambiental ${ }^{5}$. Y no porque se refieran a «materias» distintas —-sanción y medio ambiente, respectivamente-, sino porque se basan en modelos y modos de administración muy diferentes entre sí y, en definitiva, en modelos de gobierno y regulación diversos, en donde el procedimiento cumple funciones cualitativamente distintas. En el primer caso, se trata de una administración «imperativa», que actúa investida de autoridad y que, al igual que el juez, utiliza el procedimiento como herramienta de una correcta aplicación del Derecho, a fin de determinar si el interesado ha cometido o no una infracción y si esta es merecedora de sanción. En el segundo, y por el contrario, la administración opera en modo cooperativo, busca la colaboración de otras administraciones, del público en general y del sector privado, no para hallar lo que la ley haya predeterminado - porque no ha predeterminado nada-, sino para construir la mejor solución, entre todos, de cara a alcanzar un crecimiento sostenible, con ocasión de una política concreta energética o de infraestructuras, por ejemplo. El procedimiento cumple aquí una función más ambiciosa, de dirección política, ante la incapacidad de la ley para programar la solución adecuada. La comparación, en otras palabras, ha de hacerse «por pares», esto es, con iguales, tanto dentro del propio ordenamiento jurídico como fuera de él.

Esa clasificación, sea o no con pretensiones comparatistas, ofrece un mapa o sistema no solo descriptivo, sino también de carácter prescriptivo, en la medida en que pone en evidencia los déficits —en términos de principio democrático, de Estado de Derecho o de eficacia- que cada procedimiento pueda presentar. Comencemos, pues, desde el principio.

\section{I.2. El origen procesal del procedimiento administrativo: cuando la conquista histórica resulta insuficiente}

La idea de secuenciar el proceso decisorio - esto es, de establecer una serie o sucesión de actuaciones encadenadas conducentes a la toma de decisiones- es tan antigua como el Derecho mismo. Con la instauración de la división de poderes, se abriría paso la necesidad de establecer un procedimiento específico para cada uno de ellos. Las decisiones jurisdiccionales — sentencias, autos, providencias - se adoptarían a través de un proceso. Las decisiones parlamentarias — desde la entrada del proyecto o de la proposición en la cámara hasta su aprobación y promulgación - seguirían su propio cauce: procedimientos legislativos. Finalmente, el ejecutivo y la administración sujetarían sus decisiones a

4 Véase, a título de ejemplo, los artículos 134 y siguientes de la ley de procedimiento española 30/1992.

5 Véase, por ejemplo, los artículos 6-25 de la Ley 9/2006, de 28 de abril, sobre la evaluación de los efectos de determinados planes y programas en el medio ambiente. 
un procedimiento administrativo dotadas de autoridad - concesiones, permisos, sanciones, etcétera-.

El diseño de las primeras leyes de procedimiento administrativo, tanto en el siglo XIX como en el siglo XX, se inspira abiertamente en el esquema judicial, civil o penal, en función de la decisión a adoptar. Lo mismo, y aún antes, hará la jurisprudencia para hacer frente a las cuestiones suscitadas en torno a la toma de decisiones por parte de la administración. Encontrará soluciones y criterios a partir del modelo que ofrece el veterano proceso judicial. La mimetización del modelo judicial se extiende tanto a las fases o secuencias en que se articula el procedimiento - iniciación, instrucción, y terminación - y a los principios que, aunque en forma más simplificada, las rigen, como al modelo imperativo que lo preside y que no es sino una expresión del ejercicio de autoridad. Al igual que la sentencia judicial, el producto estrella del procedimiento administrativo (el acto administrativo) está dotado de las presunciones y de las prerrogativas propias de las decisiones jurisdiccionales, a la vez que se halla adornado de las técnicas coercitivas propias del poder. En realidad, se imita o transpone el «concepto» mismo. Es decir, toda decisión formal o con alguna relevancia, que afecte a los derechos e intereses de los ciudadanos, y/o que tenga trascendencia para el interés general, ha de cursarse a través de un procedimiento administrativo, como garantía de acierto y de respeto de la legalidad subjetiva. Dicho de otro modo, el procedimiento administrativo se reserva para las decisiones formalizadas de la administración, como mecanismo de aplicación del Derecho. La administración se sirve del procedimiento, como el juez del proceso para hacer hablar a la ley, pues uno y otro actúan aquí como boca de la ley. Ahí hallará el procedimiento administrativo su grandeza y sus evidentes conquistas, al tiempo que sus limitaciones intrínsecas - como luego se verá-, puesto que, a contrario, cualquier otra actividad de la administración - sea esta de carácter prestacional o de servicio, de naturaleza material, o de Derecho privado-, así como toda acción del sector privado con un determinado alcance o impacto para el interés general, quedarán fuera del paraguas del procedimiento administrativo. La legislación tradicional de procedimiento se circunscribe a las administraciones públicas y a las entidades de Derecho público cuando ejerzan potestades administrativas desde el siglo XIX hasta nuestros días, siempre y cuando actúen con autoridad o imperium.

Las razones por las que se inspira el procedimiento administrativo en el espumea judicial son variadas. Una primera causa parece circunstancial. Y es que las primeras reglas de procedimiento administrativo relativas a la formación de la voluntad de la administración son de creación jurisprudencial —el reconocimiento de los derechos de defensa, por ejemplo_- El proceso judicial representaba el método que tenían más a mano los jueces y tribunales para colmar las lagunas y resolver con

TRES GENERACIONES DEL

PROCEDIMIENTO ADMINISTRATIVO

THREE

GENERATIONS OF ADMINISTRATIVE PROCEDURE 
fiabilidad y consistencia las demandas planteadas. Sin embargo, la razón más profunda de ese trasvase es de carácter estructural, y reside en el modelo que encarna el proceso judicial, particularmente idóneo cuando se trata de resolver asuntos relacionados con los derechos e intereses de los ciudadanos, esto es, de ir a la ley para hallar la solución que esta haya predeterminado para el caso en cuestión. Por poner algunos ejemplos, si se tiene o no derecho a un permiso o autorización, si se es o no el mejor candidato a un puesto de la función pública o determinar cuál es la oferta económicamente más ventajosa en la licitación de un contrato son cuestiones que podrán ventilarse adecuadamente a través de un proceso o, lo que es lo mismo, de un procedimiento llamado «administrativo» porque es la administración y no el juez la que lo impulsa.

En definitiva, este es el procedimiento administrativo que acapara la atención de la doctrina y a la que reservamos la expresión misma. Es la clase de procedimiento del que hablan de ordinario las leyes de procedimiento administrativo contemporáneas y del que se ocupaban ya las primeras leyes decimonónicas, y sobre el que se debate en tantos foros y congresos a fin de mejorar sus prestaciones y funcionalidad — principios, simplificación, instrucción, etcétera-. Es, al fin y al cabo, el procedimiento concebido o representado en una imagen lineal, como conjunto de actos de autoridad encadenados con el objeto de dictar una resolución final dotada de autoridad.

Este es, en otras palabras, el procedimiento administrativo que venimos en llamar «de primera generación», que constituye sin duda un elemento esencial de todo Estado de Derecho y representa, probablemente, la mejor aportación que ha realizado el Derecho administrativo en términos sistemáticos o «macroeconómicos», más allá de la evidente conquista histórica que representa el singular y ulterior control jurisdiccional. Hablamos, en otras palabras, del procedimiento administrativo como proceso decisorio, cualesquiera que sean las formas que las decisiones encarnen: acto administrativo (protagonista indiscutible), contratos, normas, planes o programas, como método de la correcta aplicación del Derecho, de una aplicación imparcial, igual para todos y sin discriminaciones, previsible y fiable.

Estos indudables logros, sin embargo, no impiden hacer una fácil constatación. Y es que la administración no se limita a dictar resoluciones formales en aplicación del Derecho, como hacen los jueces y tribunales, puesto que, de entrada, no solo interpreta y aplica el Derecho, sino que crea y establece nuevas reglas y normas. Dicho de otro modo, la administración hace muchas más cosas que decidir, y es que tiene muchos más «modos» que el imperativo o jerárquico, propio del dictado de los actos administrativos. En la práctica, ello significa que el procedimiento tipo — de primera generación — se ha quedado corto, 
y que deviene en escasamente representativo de la realidad administrativa contemporánea.

En primer lugar, en efecto, la actividad administrativa no se resuelve ni se agota en un proceso decisorio. La administración decide, sí, pero también estudia, evalúa, recaba, procesa e intercambia información. Decide, sí, pero realiza prestaciones y servicios, por sí misma o a través de múltiples fórmulas, por ejemplo ${ }^{6}$.

En segundo término, la administración actúa y opera sobre las premisas y los conceptos de autoridad y jerarquía, en modo imperativo — de «ordeno y mando»—, esto es, «vestida de uniforme», en ejercicio de autoridad - para otorgar o denegar una licencia o imponer una sanción-. Pero también se viste «de civil» o «de paisano» — para prestar un servicio a través de una organización de Derecho privado- - La administración trabaja en forma autosuficiente cuando sabe lo que quiere, pues se limita a aplicar el Derecho — si otorga o no esa licencia-, pero también trabaja en forma colaborativa y en red con otras administraciones y el sector privado, dentro y fuera de las propias fronteras, cuando no es omnisciente o cuando las dimensiones del problema superan en mucho su tamaño y capacidad — por ejemplo, para indagar si las cenizas de un volcán impiden volar, para determinar las medidas a adoptar para evitar una pandemia, a fin de determinar la radioactividad en los alimentos después de un escape nuclear, etcétera-.

Pese a esas otras vidas de la administración, la legislación tradicional de procedimiento administrativo, anclada en sus orígenes procesales, induce a creer que regula la actividad principal de la administración como si de un código se tratara, cuando, en realidad, y valga la exageración, su regulación equivaldría a una Constitución que silenciara toda referencia a los derechos de la vida moderna y redujera, por ejemplo, la libertad de expresión a la que se vierte en papel y no en formato electrónico, o a un código de comercio que ignorara la existencia de multinacionales y el comercio internacional.

\section{PROCEDIMIENTOS DE PRIMERA GENERACIÓN II.1. Cuatro notas características}

En términos muy simples, podríamos destacar, en lo que ahora importa, cuatro notas que singularizan a los procedimientos administrativos de primera generación, que son aquellos que tienen su sede en la legislación tradicional.

TRES

GENERACIONES

DEL

PROCEDIMIENTO ADMINISTRATIVO

THREE

GENERATIONS OF ADMINISTRATIVE PROCEDURE 
- (i) El procedimiento administrativo de primera generación constituye ante todo un instrumento o mecanismo para la correcta aplicación de Derecho en manos de la administración imperativa, especialmente diseñado para el dictado de actos administrativos singulares (decisiones unilaterales), potencialmente de gravamen o restrictivos de derechos. Ello justifica las garantías que el procedimiento establece, tanto en lo que hace a la iniciación, comparecencia e instrucción, como en punto a la resolución definitiva, el recurso administrativo o la revisión.

- (ii) El procedimiento cumple una función adjetiva, accesoria o subordinada respecto del Derecho material, es decir, una función instrumental o al servicio de la mejor aplicación del Derecho. Lo relevante a la postre es que la decisión adoptada sea correcta en términos jurídicos. Si la decisión de la administración resulta conforme a Derecho, las infracciones de procedimiento, salvo que causen indefensión, no adquieren de ordinario trascendencia invalidante - hay que aclarar que si la denegación de una licencia es correcta, una infracción formal o de procedimiento puede resultar irrelevante-. Por ello, si el acto se ajusta materialmente a lo que la ley haya dispuesto, los vicios de forma resultarán fácilmente subsanables — piénsese, por ejemplo, en la regla de la anulabilidad y en el criterio de las irregularidades no invalidantes, y en sus equivalentes en tantos otros ordenamientos- ${ }^{7}$. En ese sentido, el procedimiento tiene un carácter adjetivo. La consecuencia más plástica y conocida reside en la teoría de los vicios del acto y del procedimiento, donde se aprecia un cierta indulgencia o, si se quiere, una menor severidad: la nulidad absoluta como excepción., la regla de la anulabilidad - matizada a su vez con el criterio de las irregularidades no invalidantes ${ }^{8}$-, la subsanabilidad y conservación, entre otras.

- (iii) El procedimiento administrativo se estructura conforme a una visión procesalista que todo lo impregna: las fases en que se articula, las potestades de impulso, la prueba y su práctica, las formas de terminación, etcétera.

7 Por ejemplo, en la legislación general en vigor en España, pueden verse los artículos 62-67 de la ley 30/1992 de procedimiento administrativo (Ley de Régimen Jurídico de las Administraciones Públicas y del Procedimiento Administrativo Común (30/1992), del 26 de noviembre de 1992). Asimismo, véase: BARNES, J. El procedimiento administrativo en el Derecho comparado. Madrid: Civitas, 1993.

8 Por ejemplo, en el caso español, el artículo 63 de la ley 30/1992 dispone lo siguiente:

«1. Son anulables los actos de la Administración que incurran en cualquier infracción del ordenamiento jurídico, incluso la desviación de poder.

2. No obstante, el defecto de forma solo determinará la anulabilidad cuando el acto carezca de los requisitos formales indispensables para alcanzar su fin o dé lugar a la indefensión de los interesados.

3. La realización de actuaciones administrativas fuera del tiempo establecido para ellas solo implicará la anulabilidad del acto cuando así lo imponga la naturaleza del término o plazo». 
- (iv) Constituye, en fin, un proceso decisorio, puesto que, como ya notábamos, sirve para dictar actos, aprobar normas, celebrar contratos, elaborar normas, redactar planes, confeccionar proyectos, entre otras funciones.

Dentro de esta categoría podrían incluirse, por ejemplo:

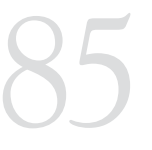

TRES

GENERACIONES DEL

PROCEDIMIENTO ADMINISTRATIVO

THREE

GENERATIONS OF ADMINISTRATIVE PROCEDURE

Con todo, la pertenencia a esta generación no viene determinada por la tradición o la «naturaleza de las cosas», sino, en última instancia, por el medio o hábitat en el que se cursa el procedimiento: una administración imperativa, un proceso jerárquico, una ley con programación material a ejecutar por la administración.

Aunque un procedimiento administrativo así concebido deje muchas cosas fuera (cuadro 1) y responda al específico «modo» de administración que no agota todas las opciones (cuadro 2), lo cierto es que posee una extraordinaria relevancia y efectos multiplicadores.

Nótese, a tal propósito, primero, que la evolución y madurez del Derecho administrativo corre paralela, en muchos casos, a la emergencia del procedimiento administrativo como institución, como sucedió paradigmáticamente con la ley federal estadounidense de procedimiento (APA, 1946), y como aún hoy acontece en tantos países - Europa del Este, América Latina, sudeste de Asia, por ejemplo-. Segundo, que el procedimiento es a la administración lo que la Constitución al Estado: la norma básica que acompaña en la transformación de la realidad a las funciones que asume la Administración. Tercero, que el procedimiento 
sirve de correa de transmisión en la administración de valores fundamentales propios de un Estado democrático de Derecho — racionalidad, control y rendición de cuentas, motivación, participación, transparencia, consenso, etcétera-. Cuarto, que el procedimiento, en cuanto guía de la acción administrativa, facilita la lucha contra la corrupción y la discriminación, ya que hace previsibles y fiables sus decisiones, garantiza la independencia y neutralidad en la aplicación del Derecho, y promueve su conformidad con los derechos fundamentales. Quinto, que racionaliza el trabajo administrativo. Y sexto, que el procedimiento se ha mostrado notablemente expansivo en numerosos países, al incorporar, más allá de trámites, derechos o principios procedimentales, parámetros materiales de actuación - igualdad y no discriminación, proporcionalidad, entre otros-, normas de acceso a la información administrativa, la teoría del órgano administrativo —creación, competencia, relaciones-, la teoría del acto administrativo y de los vicios, las fuentes del Derecho administrativo — como en el caso peruano—, etcétera.

Pese a ello, y como queda claro, la institución del procedimiento administrativo, tal y como se encuentra regulada en la legislación tradicional, ofrece un retrato insuficiente de la realidad.

\section{II.2. La distancia o el desfase histórico entre la legislación tradicional (procedimiento de primera generación) y la realidad}

El procedimiento constituye, como acaba de notarse, la columna vertebral del Derecho administrativo, y representa la pieza que contiene mayor información genética sobre el Derecho público en un tiempo y espacio determinados, como si de una piedra de Rosetta se tratara. La lectura de una Constitución ofrece, sin duda, un extraordinario retrato de la sociedad de su tiempo, pero de ella no se deriva el grado de consecución de los objetivos que persigue, ni la efectividad y plenitud de sus derechos y los contenidos de estos, los cuales están siempre fijados por la jurisprudencia ulterior. La legislación de procedimiento, por su parte, ayuda más que ninguna otra institución del Derecho público a desvelar, entre otras cosas, los siguientes rasgos o elementos del sistema:

- Las modalidades o clases de administración actuante — de «ordeno y mando» o de policía-, de administración prestacional o de garantía del resultado prestacional, de administración estructurada jerárquicamente — como si de una unidad autárquica se tratara - o de administración en forma de red, abierta a la colaboración interadministrativa y público-privada, etcétera. 
- La posición real que ocupa el ciudadano en el sistema: si es tratado como un ciudadano mudo, como mero destinatario de la acción administrativa o como un ciudadano activo.

- La organización interna y el modo de gestión de los asuntos públicos.

- La línea de separación entre el Estado y la sociedad —entre la administración y el ciudadano-

- El grado de eficacia que se pretende asegurar en la consecución de los objetivos. Es decir, si el procedimiento se preocupa de la fase de aplicación — supervisión y revisión-.

- La forma de limitación y control de la administración.

- La noción de Estado y de empleado público.

- Las relaciones de la administración con los demás poderes.

- Eventualmente, la teoría del acto y de los vicios, la teoría de la organización, etcétera.

Sin embargo, la legislación actual de procedimiento no serviría para retratar a la administración contemporánea a comienzos del siglos XXI. La ley española 30/1992, en su regulación del procedimiento, como tantas otras en el panorama comparado, no es representativa de la realidad actual (véase cuadros 1 y 2). La lectura de esta y otras leyes es similiar a la de esas constituciones que seguían recogiendo el voto censitario pese a haber sido superado en la legislación ordinaria.

Poca información se ofrece sobre una realidad más compleja. Y ello por dos razones fundamentales: (i) porque no da cuenta de otras «vidas» o modos de ser de las administraciones actuales, y (ii) porque tampoco la da de otras formas de gobierno ni de regulación que no sean las tradicionales.

Otras vidas que importan a la institución del procedimiento y que encuentran escaso o nulo eco en las leyes tradicionales:

- La vida privada de la administración: icómo ha de decidir y comportarse la administración cuando se viste de civil, deja su «uniforme» y actúa como una organización sujeta al Derecho privado? ¿Qué principios habrían de regir o inspirar esa actuación?

- La vida pública de entidades privadas que llevan a cabo actividades de interés general: icómo han de decidir y comportarse los sujetos privados cuando realizan tareas o funciones que se consideran de interés general en relación con terceros?

TRES

GENERACIONES

DEL

PROCEDIMIENTO ADMINISTRATIVO

THREE

GENERATIONS OF ADMINISTRATIVE PROCEDURE 
- La vida exterior de la administración más allá del Estado: ¿cómo han de decidir y comportarse más allá de las fronteras del Estado cuando la administración cruza la frontera?

- La vida pública de la administración cuando no actúa con instrumentos formales, imperativos o vinculantes: adopta decisiones informales, aprueba normas de Derecho indicativo o blando (soft law) como guías o recomendaciones, negocia, busca el consenso, informa (estado de la salud pública o de la economía).

Otros modelos de gobierno que subyacen a las distintas generaciones de procedimiento:

- Tampoco reflejan la legislación tradicional o de primera generación las nuevas formas de gobierno y de regulación administrativas, que son distintas a las tradicionales. Esto hace referencia a los nuevos métodos de dirección, regulación y gobernanza sustentados, en esencia, sobre una intensa colaboración públicoprivada e interadministrativa. La legislación de procedimiento muestra una sola clase de administración - la imperativa o de policía- y un único modelo de gobierno, de arriba hacia abajo (véase el numeral III.1 y los cuadros 2 y 3 ).

- En suma, la institución del procedimiento administrativo, en el plano legislativo y doctrinal, se ha mantenido invariable pese a las profundas transformaciones del Derecho administrativo contemporáneo.

- ¿Cómo ha evolucionado el Derecho en esa encrucijada?

- Con una segunda generación de procedimientos, muy incompleta, marcada por la misma idea de una administración jerárquica, imperativa y autosuficiente.

- Con una incipiente tercera generación, basada en formas de colaboración, alejadas de toda autosuficiencia.

\section{SEGUNDA GENERACIÓN: NORMAS ADMINISTRATIVAS APROBADAS POR ADMINISTRACIÓN JERÁRQUICA}

La segunda generación de procedimientos surge con fuerza a partir de la segunda mitad del siglo XX, y tiene por objeto la aprobación de normas administrativas infralegales - reglamentos ejecutivos o independientes, planes territoriales o urbanísticos, circulares de organismos reguladores o agencias independientes, ordenanzas locales, etcétera-. Teóricamente, el procedimiento reglamentario se habría de construir sobre la imagen del proceso legislativo. Ahora bien, como son pocas las reglas que disciplinan la elaboración de leyes, este procedimiento se acoge en 
buena medida a la plantilla del proceso judicial'9. Se trata, en todo caso, de un proceso decisorio.

Con alguna notable excepción ${ }^{10}$, la producción normativa que contemplan las leyes de procedimiento se canaliza a través de un proceso regulatorio que se desarrolla de arriba hacia abajo, en manos de una administración jerárquica e imperativa, y con una participación ciudadana que tiene lugar en una fase tardía, cuando la norma está ya por completo prefigurada.

Se trata en la mayor parte de los casos de procedimientos un tanto rudimentarios ${ }^{11}$. Esto no deja de ser paradójico si se tiene en cuenta la trascendencia que la actividad reglamentaria ha adquirido desde la segunda posguerra, tanto por el número de normas infralegales aprobadas en relación con las leyes, como por su calidad, y a la luz del impacto real que el reglamento cumple en la sociedad postindustrial, en ámbitos como el medio ambiente, la seguridad alimentaria, la seguridad pública, la salud pública, la regulación de los mercados financieros, el planeamiento, etcétera. De ordinario, además, la legislación general se ha concentrado en la aprobación de reglamentos ejecutivos —o de desarrollo de las leyes emanadas del parlamento-, con lo que ha dejado fuera de su consideración la gestación de otras muchas clases de normas administrativas. En ese sentido, sorprende que para la elaboración de una norma reglamentaria de un organismo regulador o de un banco central se puedan exigir los mismos $-\mathrm{O}$ menos - requisitos procedimentales que para la elaboración de un reglamento que se limita a desarrollar una ley previa.

Dentro de esta generación, pueden citarse dos tipos característicos: los procedimientos de elaboración de disposiciones reglamentarias y aquellos otros que tienen por objeto la gestación del planeamiento urbanístico y territorial.

La legislación tradicional tampoco ha prestado atención a cuestiones que hoy han adquirido una notable importancia, como pueden ser la elaboración de normas no vinculantes - Derecho indicativo, blando o soft law-, la producción normativa que emana de la autorregulación privada, o las normas — vinculantes o no- construidas más allá del Estado.

Esa tendencia comienza a ser corregida debido a los impulsos de las múltiples iniciativas tendentes a mejorar las políticas regulatorias en el plano interno, regional (europeo) e internacional —señaladamente,

9 Véase: RuBIN, E. «It's Time to Make the Administrative Procedure Administrative».

10 Como en el caso de la ley de procedimiento administrativo estadounidense de 1946. Véase: STRAUSS, Peter L. «Los procedimientos de elaboración de reglamentos y disposiciones administrativas en EE.UU.». En Javier Barnes (editor). La transformación del procedimiento administrativo. Sevilla: Editorial Derecho Global - Global Law Press, 2008.

11 Por ejemplo, el artículo 24 de la ley española 50/1997 del gobierno.

TRES

GENERACIONES DEL

PROCEDIMIENTO ADMINISTRATIVO

THREE

GENERATIONS OF ADMINISTRATIVE PROCEDURE 
de la Organización para la Cooperación y el Desarrollo Económico (OCDE) y del Banco Mundial-.

\section{TERCERA GENERACIÓN: ACTOS, NORMAS Y POLÍTICAS PÚBLICAS ELABORADOS EN EL ENTORNO DE LAS NUEVAS FORMAS DE GOBERNANZA}

Fuera de los procedimientos de primera y segunda generación, la administración no es autárquica, puesto que no lo sabe todo ni lo puede todo, por lo que, en consecuencia, necesita de las demás administraciones y del sector privado para realizar numerosas políticas públicas. Cuando la magnitud de los problemas excede la talla de una determinada administración o de la del Estado, y/o cuando las cuestiones que han de afrontarse están marcadas por la incertidumbre, es necesario colaborar y gobernar de un modo diferente al tradicional. Así surge lo que puede denominarse como «gobernanza» en ámbitos y sectores diversos, como los del medio ambiente, de la regulación de los mercados financieros, de la salud pública, de la energía, de la seguridad pública, etcétera.

\section{IV.1.Las coordenadas de las nuevas formas de gobierno y administración: la gobernanza administrativa como presupuesto y entorno de los procedimientos administrativos de tercera generación}

El sistema de producción normativa y de gobierno, heredados del Estado liberal del siglo XIX, se caracteriza por tres notas: primero, el Derecho emana de un único centro; segundo, el curso del proceso regulatorio desciende de arriba hacia abajo; y, tercero, la administración se concibe a sí misma como una organización destinada a ejecutar o a aplicar la ley, haciendo uso de técnicas coercitivas (cuadro 3).

Ese sistema se asienta en la premisa de que la ley formal todo lo contempla. A partir de ese postulado, se construye el edificio:

- El Estado es el único «productor» de normas, por lo que la regulación tiene, en consecuencia, carácter estado-céntrico.

- La administración se estructura jerárquicamente y actúa de modo imperativo para llevar a su debido efecto lo establecido en la norma.

- Las leyes se resuelven en órdenes o mandatos positivos y en prohibiciones.

- La regulación se articula en torno a dos fases netamente diferenciadas: la creación de la norma y su aplicación. Se fundamenta, por tanto, en el binomio «programación-ejecución». 
La primera, reservada al parlamento, y la segunda a la administración. La discrecionalidad —en virtud de la cual el legislador difiere a la administración la respuesta o la decisión - tiende a concebirse en el plano teórico como algo excepcional, un privi-

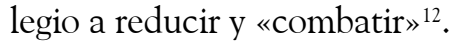

Esta forma de legislar y administrar ha perdido su monopolio como consecuencia de las profundas transformaciones del Estado y de la administración contemporáneos ${ }^{13}$, que viene a ser consecuencia inmediata, entre otros factores, de la apertura de tres fronteras celosamente guardadas durante largo tiempo ${ }^{14}$.

La primera es la caída del muro que divide el plano nacional y el supranacional. La administración y el Derecho administrativo ya no son solo, ni exclusivamente, «estado-céntricos». La acción exterior de las administraciones nacionales ha crecido exponencialmente, a ello se añade la existencia más allá del Estado de una variada gama de organismos reguladores, públicos, privados y mixtos, con efectos multiplicadores para las políticas públicas nacionales. Al fin y al cabo, las políticas relevantes ya no son solo «nacionales» $\mathrm{O}$ «domésticas» ${ }^{15}$.

La disolución de la segunda frontera - la que separaba lo público y lo privado - tampoco ha pasado desapercibida. La permeabilidad entre ambas esferas resulta no menos trascendente. El Estado y la sociedad, y la administración y el ciudadano no constituyen ámbitos aislados que nunca se tocan. A su vez, la administración no define en solitario en tantos sectores lo que al interés general conviene: si un medicamento es apto para el consumo humano, por ejemplo. También se refiere a temas de diversa índole; desde cuál sea la mejor tecnología disponible hasta la definición del plan de estudios más adecuado. Ni el sector privado puede vivir desinteresado de la regulación. Hoy día la administración y la sociedad tienden a actuar de consuno, como socios que se necesitan. La co-regulación y la autorregulación no son sino dos manifestaciones más de las nuevas estrategias regulatorias en las que se implica activamente al sector privado ${ }^{16}$.

La tercera frontera que parece relativizarse es la que distinguía la formulación de las políticas de su gestión posterior, así como la creación del

12 Para mayor abundamiento, me remito a mi trabajo «Reforma e innovación del procedimiento administrativo». En La transformación del procedimiento administrativo. Ob. cit., pp. 31 y siguientes. 13 Sobre el tema, véanse las dos primeras obras colectivas citadas en la nota 6 .

14 Sobre este tema, y para mayor desarrollo de cuanto aquí se dice, me remito a mi trabajo «Towards a third generation of administrative procedure». En Rose-Ackerman y Peter L. Lindseth (editores). Comparative Administrative Law. Yale: Edward Elgar Publishing, 2010.

15 Véase: BARNES, Javier. «Un estatuto de autonomía y una constitución del Siglo XX». Revista de Administración Pública. Número 173, mayo-agosto (2007), pp. 293-315, especialmente pp. 303 y siguientes, Madrid.

16 Véase, por ejemplo, los artículos 18-23 de «Legislar mejor», acuerdo interinstitucional del parlamento, del consejo y de la comisión (Diario Oficial C 321 de 31.12.2003). 
Derecho y de su aplicación. Las rígidas fases en que se escalonaba el proceso regulatorio - la creación de reglas sustantivas a cargo del legislador primero, y, más tarde, su aplicación confiada a la administración- parecen desdibujarse en numerosos sectores, como consecuencia de la incapacidad de la ley para anticiparse a la realidad y dirigir, en consecuencia, la acción administrativa en los términos en que tradicionalmente era concebida esa vinculación o sometimiento. En tantos casos, la administración ya no encuentra en la ley la receta a aplicar. Si la ley no puede definir cuáles sean las sustancias químicas peligrosas, el crecimiento sostenible en cada caso, los estándares técnicos que hayan de seguirse para la elaboración de un producto o la prestación de un servicio, por dónde, en qué forma y con qué usos constructivos ha de crecer la ciudad, o qué determinaciones se han de adoptar para asegurar la competitividad de un concreto mercado de las telecomunicaciones, por poner algunos ejemplos, habrá de idear, en compensación, mecanismos, foros y reglas para hallar la solución correcta, en términos de eficacia, de legitimidad democrática y de control. Entre otros mecanismos, el legislador establece procedimientos cualitativamente distintos a los tradicionales, a través de los cuales dirige a la administración y asegura la búsqueda de la solución más adecuada.

A través de ellos, y en un proceso continuo, se establece la regla o el criterio, se aplica y proyecta en la práctica, se vigilan y supervisan las consecuencias o efectos que generan, y se modifica o revisa la regla en función del resultado deseado - como si se tratara no de una foto fija, sino de una imagen en movimiento-. El proceso regulatorio se concibe como un ciclo en permanente movimiento.

La administración - los bancos centrales, la agencia europea del medicamento, el organismo regulador en materia de telecomunicaciones o energía, o la administración medioambientalmente responsable, por ejemplo- adquiere, en consecuencia, una mayor responsabilidad y protagonismo, puesto que su papel se aleja de la mera ejecución de una previa ley material que programe y predetermine su acción en términos condicionales - si concurre tal presupuesto de hecho, la acción a tomar o consecuencia habrá de ser la específicamente determinada-.

La apertura de esos nuevos espacios, como si de la liberación de un gas se tratara, expande el Derecho administrativo. La quiebra de esas fronteras o líneas divisorias abre, en efecto, nuevos territorios que son colonizados por nuevas formas de gobierno y regulación (cuadro 3). El modo tradicional de gobierno se había construido sobre la impermeabilidad de esas fronteras — global-nacional, público-privado, creación-aplicación-. El nuevo Derecho administrativo no es solo nacional o supranacional, sino global, no es solo Derecho público, sino también privado, no es ya solo el Derecho que controla la aplicación administrativa de las leyes y regula 
los instrumentos de que esta se sirve, sino el que guía la creación de normas, reglas, soluciones y, más ampliamente, la realización de las amplias políticas públicas que a la administración contemporánea se le confían.

$\mathrm{Si}$, en efecto, el Derecho administrativo deviene global, interactúa con el sector privado y se ocupa de la dirección de las nuevas políticas públicas a través de procesos regulatorios mucho más complejos, será necesario organizar las cosas de otro modo. Esa necesidad da lugar a nuevos modelos o modos de gobernanza para regular la salud pública, la seguridad aérea o alimentaria, los mercados financieros, las telecomunicaciones o los servicios en el marco de la Unión Europea. Y ahí el procedimiento tiene un protagonismo especial. De entrada, ha de abandonar su molde procesal para desempeñar nuevas y más altas funciones: la elaboración de normas públicas o privadas con relevancia pública - vinculantes o no-, la dirección, guía o asistencia en las nuevas políticas públicas en las que la ley no ha establecido la solución material, sino que difiere su hallazgo al procedimiento.

\section{IV.2. La función del procedimiento en el marco de la go- bernanza administrativa: el procedimiento como instrumento de dirección de la administración por parte del parlamento y de dirección del sector por parte de la administración}

El procedimiento no opera aquí como una mera herramienta para la correcta aplicación del Derecho material, ni persigue preferentemente controlar la discrecionalidad administrativa en sentido defensivo o ex post, como acontece en la primera generación. En escenarios en los que la administración no cuenta con un conjunto de soluciones preparadas por el legislador, a modo de instrucción, hoja de ruta o receta, la institución del procedimiento cumple una finalidad de dirección, y no es ya un mecanismo de aplicación del Derecho, sino de creación e innovación jurídicas, de búsqueda de soluciones. Satisface así una función de guía y dirección de carácter positivo, previo y sistemático, puesto que es capaz de condicionar ex ante y predeterminar a través suyo la acción administrativa futura en un doble sentido:

Por un lado, porque el parlamento dirige la acción administrativa en la medida en que decide cómo ha de decidir la administración en aquellos ámbitos en los que la ley no puede anticiparse a la realidad, esto es, cuando el parlamento no puede diseñar un programa de actuación concreto y determinado. Así, por ejemplo, el legislador no sabe si se podrá autorizar un futuro medicamento para el consumo humano, pero sí puede decidir cómo habrá de tomarse esa decisión: mediante el consenso de una red de científicos, sin la presencia de los laboratorios farmacéuticos, entre otras. Es decir, mediante reglas de procedimiento.

TRES

GENERACIONES DEL

PROCEDIMIENTO ADMINISTRATIVO

THREE

GENERATIONS OF ADMINISTRATIVE PROCEDURE 
Y, por el otro lado, porque la administración dirige el sector mediante la exigencia de normas de procedimiento aplicables a los restantes actores, públicos o privados, que participan en el proceso regulatorio. Así, por ejemplo, la administración puede supervisar si los códigos de conducta establecidos a través de la autorregulación sobre la prestación de cada servicio económico a escala europea - elementos estos con una clara dimensión procedimental - se han formulado con la suficiente representatividad, consenso y transparencia.

Pues bien, las reglas de procedimiento tienen mucho que decir en la elaboración y en el desarrollo de estas nuevas políticas públicas (cuadros 3 y 4). Al procedimiento le preocupa satisfacer muchas de las necesidades que aquellas demandan. Por ejemplo, una mayor responsabilidad del ciudadano en la gestión del procedimiento -instrucción del procedimiento en los supuestos de licencias medioambientales, comunicación de la actividad proyectada frente a la autorización en el ámbito de la prestación de servicios-, el constante intercambio de información entre administraciones a todos los niveles, la evaluación de las distintas opciones o alternativas, el análisis de impacto regulatorio o de costebeneficio, la supervisión de las decisiones adoptadas y su modificación cuando se detecte la desviación de los objetivos propuestos, entre otras.

\section{IV.3.Algunas notas de los procedimientos de tercera generación}

Cuando hablamos de procedimientos administrativos de tercera generación no hacemos referencia necesariamente a un proceso lineal, secuencial y sucesivo que conduce a una decisión, como sucede tradicionalmente en la primera generación.

De entrada, puede tratarse de procedimientos completos, de procedimientos compuestos o escalonados en los que intervienen diversas administraciones nacionales y supranacionales, de componentes aislados, de un principio, de un derecho, y un larguísimo etcétera.

Además, esos elementos acompañan las distintas fases en que puede descomponerse el ciclo de la política pública de que se trate: la construcción de prioridades o fijación de agenda, así como también análisis, evaluación, debate y discusión sobre las diversas alternativas, su posterior aprobación, y la aplicación supervisión y modificación de estas. Mientras los procedimientos administrativos de primera generación se limitan a aplicar la ley y, en consecuencia, adquieren una estructura característica, propia de los procesos de aplicación del Derecho, en la tercera, por el contrario, se trata de hallar una solución no escrita, de establecer una nueva regla, estándar o criterio, y de hacerlo además en conjunto - pues todos son necesarios_ y sin que tenga el producto final 
un carácter definitivo, ya que se trata de ámbitos y sectores marcados por la incertidumbre y el constante cambio y aprendizaje. La luz verde para volar ante la erupción de un volcán y la expulsión de cenizas puede cambiar a cada instante, como también la autorización ambiental o la licencia para comercializar un producto farmacéutico. Nos movemos, en otras palabras, en escenarios mucho más complejos.

En ese proceso regulatorio participan no solo las administraciones territoriales y los organismos reguladores investidos de autoridad, sino también otros actores, como entidades y empresas del sector público — sociedades sujetas al Derecho privado, por ejemplo_-, el sector privado en régimen de autorregulación —normalización de productos, por ejemplo_-, el sector privado en el desempeño o prestación de servicios de interés general —-sectores regulados_-, las organizaciones privadas subvencionadas —organizaciones no gubernamentales, por ejemplo-, contratistas de la administración, el público, entre otros. Los procedimientos de tercera generación se extienden, con las necesarias adaptaciones, por esos territorios, en la medida en que cada actor contribuye de alguna manera al conjunto.

Ello significa, en síntesis, que el procedimiento se extiende no solo a (i) las administraciones públicas cuando actúan predominantemente en modo cooperativo, sino también (ii) al sector privado en cuanto se inscribe en el proceso regulatorio - autorregulación, sectores regulados, actividades subvencionadas, incluso actividades meramente privadas-, y (iii) al sector público. Así, y a mero título de ejemplo, el procedimiento se ocupará de resolver, en el primer caso (i), los problemas de intercambio de información entre las administraciones actuantes, y entre estas y el público o los interesados — procedimientos de evaluación estratégica ambiental, procedimientos de los organismos reguladores en materia de telecomunicaciones, etcétera-, así como la forma de hallar un consenso entre los expertos — procedimientos de aprobación para el consumo humano de un medicamento, por ejemplo_- En el segundo caso (ii), el procedimiento se proyecta para asegurar, por ejemplo, la transparencia del sector privado en la toma de decisiones que afectan a los interesados, consumidores o usuarios - mediante la publicidad, el acceso a la información, o la sujeción a los principios de la contratación administrativa-, o para garantizar la representatividad de todos los productores o prestadores de servicios en el ámbito de la autorregulación, entre otras cosas. En el tercer supuesto (iii), las exigencias procedimentales pueden referirse igualmente a la transparencia en la toma de decisiones, a la publicidad de sus actividades y del presupuesto, a la observancia y control de los principios de igualdad, no discriminación y proporcionalidad, al respeto de los principios de la contratación pública, entre otros. 
El procedimiento de tercera generación es, pues, público y privado. Sirve de correa de transmisión de los valores que encierran los principios constitucionales estructurales - principio democrático, Estado de Derecho, eficacia-, y cumple una función sustantiva: participa activamente en el proceso regulatorio en modo o clave de cooperación.

Los procedimientos de tercera generación, por otra parte, comprenden procesos decisorios - decisiones singulares, normas infralegales-, y no decisorios —análisis, obtención e intercambio de información, acciones de supervisión y vigilancia, por ejemplo-.

Entre los procedimientos decisorios de tercera generación que tienen por objeto resoluciones singulares se pueden citar los procedimientos simplificados de la directiva de servicios de $2006^{17}$, en la medida en que esta norma aboga por la mera comunicación de la actividad proyectada, lo que supone, primero, una transferencia al ciudadano de la responsabilidad de observancia de la legalidad — con los costes que ello implica—, y, en segundo lugar, una colaboración interadministrativa en el espacio europeo sumamente avanzada —entiéndase que la simplificación del procedimiento significa de ordinario un trabajo técnicamente más elaborado y sofisticado por parte de la administración-.

Pero el procedimiento de tercera generación se preocupa también por la elaboración de normas reglamentarias, tales como la elaboración del planeamiento territorial y urbanístico con una participación y diálogo entre administraciones y el público más intenso y efectivo, la elaboración de las circulares de un organismo regulador en materia de telecomunicaciones, en una forma más participada o con una iniciativa mayor en manos de los operadores para hacer propuestas, asimismo, la elaboración de documentos de Derecho indicativo o soft law - como manuales, recomendaciones, vademécum, revisión por pares, entre otros-, y reglas de representatividad de los sujetos privados dentro de la autorregulación cuando elaboran normas técnicas.

Son numerosas, y, en ocasiones, más que relevantes, las fórmulas, los criterios o los principios de procedimiento que, sin desembocar directamente en la toma de decisiones, tienen por objeto satisfacer las múltiples necesidades de las nuevas formas de trabajo y la elaboración de las políticas públicas: obtención e intercambio de información ${ }^{18}$, consultas para identificar las prioridades de una determinada política,

17 Directiva 2006/123/CE del Parlamento Europeo y del Consejo, del 12 de diciembre de 2006, relativa a los servicios en el mercado interior (Diario Oficial L 376 del 27 de diciembre de 2006).

18 Por ejemplo, en lo que hace a la CMT, responden a esta idea del procedimiento como intercambio de información los requerimientos de información de carácter formal a que se refiere el artículo 9 LGT, los requerimientos informales de información por cualquier medio (correo electrónico, teléfono), el intercambio de información sin requerimiento (entre organismos reguladores, por ejemplo, a través del European Regulatory Group o cualquier otro foro) y las comunicaciones constantes de los operadores hacia el organismo regulador (sin requerimiento previo), etcétera. 
colaboración entre organismos reguladores, evaluación periódica de las opciones políticas, análisis de los efectos, etcétera.

\section{TRES GENERACIONES DE PROCEDIMIENTO} ADMINISTRATIVO:TRES «TEORÍAS GENERALES» La manera en la que nosotros pensamos el procedimiento está muy lejos de corresponder con la manera en la que se llevan a cabo o se cursan los procedimientos en la realidad. Hay modelos muy diferentes - los que llamamos «generaciones»— que, sin embargo, se explican a la luz de una teoría que tan solo da cuenta, y muy parcialmente, de uno de todos esos modelos.

Con la expresión, conscientemente exagerada, que encabeza el presente epígrafe, se quiere llamar la atención sobre la necesidad de distinguir y matizar, hasta donde sea necesario, cada uno de los pilares o elementos del procedimiento administrativo clásico. La instrucción del procedimiento, la participación, la motivación de las decisiones, los vicios del procedimiento - mucho más exigente en la última generación-, la estabilidad y conservación del producto final, y tantas otras cosas relacionadas a él no admiten una consideración unitaria y uniforme.

Veámoslo, a mero título de ejemplo, con la transparencia.

Aquí, como en otros elementos, no se puede hablar de «la» transparencia, sino de «las» diversas formas de transparencia, según el tipo de procedimiento del que se trate y, en última instancia, de acuerdo con las distintas formas o modos de regulación y administración en los cuales aquel se inscriba. La transparencia constituye, en ese sentido, un fenómeno transversal que recorre y atraviesa el terreno de las tres generaciones.

En lo que aquí interesa - la modulación o proyección de la transparencia en los procedimientos administrativos-, cabe apreciar una diversa fisiología y finalidad en cada generación, y, dentro de estas, en cada subtipo o especie. En otras palabras, el derecho de acceso a la información administrativa, cuando menos en el marco del procedimiento, no es reconducible a la unidad, a un régimen unitario, puesto que, según se inserte en una u otra generación y especie, responderá a funciones y estructuras diversas. Una cosa es, por ejemplo, el acceso a la información administrativa con fines de defensa de los propios derechos e intereses, y otra, muy distinta, el acceso a la información medioambiental del público como instrumento de supervisión y control de la legalidad medioambiental —y, más ampliamente, de la política en materia de medio ambiente o el derecho de acceso a la información para su reutilización-. Son magnitudes diferentes, sin perjuicio de que participen de raíces y fundamentos comunes. 
Así, en buena parte de los procedimientos de aplicación del Derecho material o de primera generación, la transparencia se expresa, por ejemplo, en el derecho de acceso al expediente en que se articula el procedimiento, o en el acceso a otros expedientes análogos para su contraste o comparación, así como en una motivación adecuada de la decisión adoptada. Es decir, presenta una evidente vertiente defensiva. El acceso a la información, en efecto, permite diseñar una estrategia defensiva frente a actos administrativos potencialmente de gravamen o restrictivos de derechos. En otros casos, por el contrario, como acontece en los procedimientos de carácter o contenido prestacional, la transparencia asegura el ejercicio de otros derechos, como en materia de medio ambiente. La información facilita la elección. Así, por ejemplo, el procedimiento de solicitud de información ambiental, si desemboca en la entrega de la información requerida, podrá permitir el control y la supervisión de la acción administrativa y del sector privado, y actuar en consecuencia. El ciudadano se convierte en un eventual agente fiscalizador del respeto al medio ambiente. La transparencia aquí constituye un instrumento regulatorio: el público como sujeto activo, al que se le reconoce la acción popular ${ }^{19}$. Otro supuesto lo constituye el procedimiento de solicitudes de reutilización de documentos administrativos —información social, económica, geográfica, meteorológica o turística y sobre empresas, patentes y educación-, sea o no con fines comerciales, cuyo objetivo radica en asegurar un mercado interior en el acceso a materia prima tan esencial como la información administrativa —en condiciones equitativas, proporcionadas y no discriminatorias- . La transparencia en el procedimiento de autorización y de puesta a disposición del documento asegura esas condiciones, así como la observancia de las normas de la competencia ${ }^{20}$.

En suma, cuando se trata de un procedimiento que puede desembocar en un acto potencialmente limitativo acordado por una administración imperativa, la transparencia contribuye a la defensa individual. Cuando, por el contrario, estamos ante procedimientos con un cierto carácter prestacional — como el de acceso a la información medioambiental o el de reutilización de la información administrativa-, la transparencia cumple otras finalidades de naturaleza regulatoria. Es decir, funge como instrumento de control y supervisión, y de garantía de la competencia en el mercado único del bien en cuestión —como sucede en el caso europeo, por ejemplo-.

19 Véase los artículos 20 y siguientes de la ley 27/2006, del 18 de julio, por la que se regulan los derechos de acceso a la información, de participación pública y de acceso a la justicia en materia de medio ambiente (incorpora las directivas 2003/4/CE y 2003/35/CE).

20 Ley 37/2007, del 16 de noviembre, sobre la reutilización de la información del sector público (artículos 10 y siguientes), así como la Directiva 2003/98/CE del Parlamento Europeo y del Consejo, del 17 de noviembre de 2003, relativa a la reutilización de la información del sector público. 
En los procedimientos de segunda generación, y habida cuenta de que se trata de procesos que siguen un curso de arriba hacia abajo o de secuencia jerárquica en donde la administración sabe lo que quiere - por ejemplo, tiene clara la filosofía que ha de presidir un anteproyecto de ley, el desarrollo reglamentario que ha de darle a una concreta ley, o el contenido de un plan urbanístico-, la transparencia garantiza el conocimiento anticipado de lo perseguido y, por consiguiente, la defensa y participación del colectivo afectado y, si fuera el caso, la búsqueda del consenso. Sirve, además, en un sentido más amplio, como presupuesto o nutriente del derecho a ser informado.

En la tercera generación, la transparencia cumple funciones diversas y heterogéneas, como heterogéneos son los procedimientos o elementos procedimentales que conviven bajo su rúbrica. Si el entorno y hábitat en el que estos viven reside en la colaboración — sea entre administraciones y/o con el sector privado-, la transparencia representa aquí el aire que respira el entero proceso, el presupuesto inexcusable para que una tal colaboración pueda producirse, primero, cuando esta se extiende a todas las fases del ciclo de las diversas políticas públicas - fijación de prioridades y agenda, determinación de las líneas básicas, ponderación de las diversas opciones, aprobación definitiva, constante revisión sobre su efectividad, modificación, entre otras-, y segundo, y no menos importante, cuando intervienen una multiplicidad de sujetos o actores, públicos y privados, insertos en una red o proceso regulatorio. La transparencia se convierte, entonces, en la lengua franca que permite la participación de todos. A ello se añade que cada actor estatal o no estatal, todo agente público o privado, en cuanto participantes en el proceso regulatorio, ha de ser objeto de control y ha de rendir cuentas de modo continuado, para lo que la transparencia relativa a esa específica función regulatoria resulta ser un presupuesto inexcusable.

A partir de ahí la transparencia puede adoptar una multiplicidad de expresiones, en virtud de las especies o los subtipos de procedimientos de tercera generación. Se trata de deberes u obligaciones que se sustancian a través de reglas de procedimiento. A continuación, las describimos.

- Administraciones territoriales en modo cooperativo (colaboración interadministrativa y público-privado): nos referimos, por ejemplo, la transparencia en la evaluación estratégica ambiental hace viable la participación del público y de las administraciones interesadas, ya que representa la sangre que circula por el entero sistema. El acceso a la información en el marco del procedimiento de evaluación estratégica ambiental posibilita una decisiva participación del público en general y de otras administraciones. En ese sentido, entraña una forma de corresponsabilidad de los sujetos participantes 
en el proceso regulatorio. El acceso a la información responde aquí, de nuevo, a una estrategia regulatoria: el público y otras administraciones podrán impedir opciones políticas por parte de las administraciones responsables que sean contrarias a un crecimiento sostenible, en la forma en que este haya sido apreciado en el curso del procedimiento.

- Sector público sujeto al Derecho privado: pueden servir como instrumento de control, por ejemplo, la publicidad del gasto realizado, la motivación de las decisiones adoptadas, o la contratación de acuerdo con los principios de la contratación pública y su inherente transparencia, entre otros.

- Sector privado en régimen de autorregulación: en la medida en que ostenten un poder delegado - para establecer, por ejemplo, el código de conducta de una profesión o las normas técnicas de elaboración de un producto-, la transparencia asegura la fiabilidad y representatividad de los intervinientes, a fin de asegurar que ningún sector o empresa dominante imponga sus propios criterios.

- Sector privado en el desempeño de servicios públicos o actividades de interés general («sectores regulados»): la transparencia permite elegir al consumidor e invertir con conocimiento de causa. De ahí la necesidad del acceso de la información en manos de estas compañías, y la obligación de difundir e informar tanto al público como al organismo regulador, señaladamente de aquellos extremos que afecten a la esencia del servicio: universalidad, precio razonable y calidad. En la medida en que el sector privado participa en el proceso regulatorio - mediante la prestación de servicios de interés general- resulta exigible la aplicación de las normas de acceso a la información administrativa, aunque esta deba ya serlo por analógica y al estar ajustada a la flexibilidad propia del Derecho privado. Otro ejemplo lo constituye la transparencia en la contratación que realizan, se sujete o no a los principios de la contratación administrativa; etcétera.

- Actividades de entidades privadas, con o sin ánimo de lucro, que sean subvencionadas con fondos públicos (investigación, economía, cultura, educación, cooperación, asistencia, entre otras): la transparencia podrá manifestarse en la publicación de los beneficiarios y en los motivos de la adjudicación, en la cuantía de las subvenciones, en su destino y en la justificación final, etcétera.

- Contratistas de la administración: respecto de terceros, la transparencia puede servir para informar sobre el servicio, 
así como también puede ejercer de control y de garantía, de respeto a los valores y a los derechos constitucionales, tales como la igualdad y la no discriminación, la proporcionalidad, y, según los casos, el respeto al medio ambiente y a la vida, la protección de la infancia, de la salud, entre otros.

El fundamento último que justifica la aplicación de los principios y valores del procedimiento administrativo — con las necesarias adaptaciones, desde luego- radica en que esas actividades, aunque sujetas al Derecho privado, en realidad se integran en un único y complejo proceso regulatorio. El Derecho privado opera aquí como un instrumento de colaboración e interacción con el Derecho público, no como un puerto franco ni como una zona exenta de los valores y principios que acompañan a la regulación, al gobierno y a la administración. En las últimas décadas, el sector privado ha comenzado a desempeñar relevantes funciones públicas, así como numerosas actividades económicas de interés general que antes correspondían a la administración. Es lógico esperar que las garantías y los deberes hacia los ciudadanos — que incumbían a la administración cuando realizaba por sí misma esas tareas- se desplacen ahora hacia los actores no estatales cuando se integran en este proceso regulatorio. 


\section{Cuadro 1 \\ Características y déficits que el procedimiento administrativo \\ tradicional presenta}

\section{Introducción*}

\begin{tabular}{|c|c|c|}
\hline & $\begin{array}{l}\text { Notas características del procedimiento } \\
\text { administrativo tradicional }\end{array}$ & $\begin{array}{l}\text { Algunos ejemplos de los } \\
\text { déficits de la legislación de procedimiento } \\
\text { administrativo tradicional }\end{array}$ \\
\hline $\begin{array}{l}\text { Ámbito de } \\
\text { aplicación }\end{array}$ & $\begin{array}{l}\text { El ámbito subjetivo de la legislación se cir- } \\
\text { cunscribe a las administraciones públicas y } \\
\text { a las entidades de Derecho público «cuando } \\
\text { ejerzan potestades administrativas» (artículo } \\
\text { 2.2). }\end{array}$ & $\begin{array}{l}\text { La legislación tradicional de procedimiento no } \\
\text { contempla, por ejemplo, la acción administra- } \\
\text { tiva sujeta al Derecho privado. }\end{array}$ \\
\hline Concepto & $\begin{array}{l}\text { El procedimiento administrativo constituye } \\
\text { un proceso decisorio: el procedimiento tiene } \\
\text { por objeto la adopción de decisiones que } \\
\text { habrán de desembocar en actos, contratos o } \\
\text { normas. En otras palabras, el procedimiento } \\
\text { clásico nace ligado a supuestos y situaciones } \\
\text { específicas a las que pretende dar respuesta. }\end{array}$ & $\begin{array}{l}\text { Por tanto, quedan fuera de su consideración } \\
\text { aquellos procedimientos que no están diseña- } \\
\text { dos - al menos de modo directo- para con- } \\
\text { cluir en la adopción de una concreta decisión, } \\
\text { puesto que su objeto consiste, más bien, en la } \\
\text { obtención y el tratamiento de la información. } \\
\text { Algunos ejemplos serían los procedimientos } \\
\text { de control de subvenciones, los procedimien- } \\
\text { tos de elaboración de la cartografía medioam- } \\
\text { biental, etcétera. } \\
\text { Tampoco caen dentro de la definición del } \\
\text { procedimiento como proceso decisorio las ac- } \\
\text { tividades y prestaciones materiales que lleva a } \\
\text { cabo la administración, como asistencia social, } \\
\text { mediación, entre otras. }\end{array}$ \\
\hline $\begin{array}{l}\text { Estructura y } \\
\text { morfología }\end{array}$ & $\begin{array}{l}\text { Es un proceso formal. La legislación regula la } \\
\text { actividad administrativa que se sujeta a un } \\
\text { procedimiento formalizado cuyo objeto final } \\
\text { es, igualmente, una decisión formal (acto, } \\
\text { contrato, reglamento). Asimismo, presenta } \\
\text { una estructura lineal, secuencial y sucesiva. }\end{array}$ & $\begin{array}{l}\text { Ello excluye, por ejemplo, la acción administra- } \\
\text { tiva no formalizada (negociaciones previas y } \\
\text { tratos preliminares, consultas, asesoramiento, } \\
\text { etcétera), la elaboración de los instrumentos } \\
\text { de carácter no vinculante (mecanismos de De- } \\
\text { recho indicativo o soft law, donde se incluyen } \\
\text { las recomendaciones, interpretaciones, guías, } \\
\text { etcétera). } \\
\text { Puede presentar otras estructuras o represen- } \\
\text { tar elementos o componentes de procedi- } \\
\text { miento aislados. }\end{array}$ \\
\hline $\begin{array}{l}\text { Producto } \\
\text { típico del } \\
\text { procedimiento }\end{array}$ & $\begin{array}{l}\text { El producto característico de la legislación de } \\
\text { procedimiento es el acto administrativo sin- } \\
\text { gular -en particular, de gravamen-. }\end{array}$ & $\begin{array}{l}\text { El reglamento, por ejemplo, ocupa un lugar } \\
\text { muy secundario - salvo excepciones, como } \\
\text { en la ley federal estadounidense de procedi- } \\
\text { miento-. }\end{array}$ \\
\hline
\end{tabular}




\begin{tabular}{|c|c|c|}
\hline & $\begin{array}{l}\text { Notas características del procedimiento } \\
\text { administrativo tradicional }\end{array}$ & $\begin{array}{l}\text { Algunos ejemplos de los } \\
\text { déficits de la legislación de procedimiento } \\
\text { administrativo tradicional }\end{array}$ \\
\hline $\begin{array}{l}\text { Finalidad de } \\
\text { aplicación } \\
\text { normativa / } \\
\text { creación del } \\
\text { Derecho }\end{array}$ & $\begin{array}{l}\text { El procedimiento constituye un instrumen- } \\
\text { to para la correcta aplicación del Derecho } \\
\text { material. El procedimiento administrativo } \\
\text { posee una función secundaria respecto del } \\
\text { Derecho sustantivo. Si la resolución final es } \\
\text { conforme con la legalidad, la infracción de } \\
\text { procedimiento carece de relevancia en mu- } \\
\text { chos casos. } \\
\text { El procedimiento, inserto en la clásica divi- } \\
\text { sión entre la creación del Derecho y su apli- } \\
\text { cación, se concibe esencialmente como un } \\
\text { instrumento al servicio de la segunda. }\end{array}$ & $\begin{array}{l}\text { No tiene en cuenta, por ejemplo, el procedi- } \\
\text { miento como foro para la creación o búsqueda } \\
\text { de la mejor solución no predeterminada por } \\
\text { la ley. } \\
\text { El procedimiento no acompaña el ciclo com- } \\
\text { pleto de las políticas públicas. } \\
\text { En la legislación tradicional, no se contempla } \\
\text { el procedimiento como un mecanismo que se } \\
\text { extiende a todas las fases, preparación de la } \\
\text { política pública, establecimiento de priorida- } \\
\text { des, toma de decisiones, desarrollo, aplicación, } \\
\text { revisiones y modificación, control, etcétera. }\end{array}$ \\
\hline $\begin{array}{l}\text { Actividad de } \\
\text { ejecución }\end{array}$ & $\begin{array}{l}\text { La única actividad de ejecución o de aplica- } \\
\text { ción del Derecho que se recoge es la ejecu- } \\
\text { ción forzosa. Se parte de la premisa de que } \\
\text { las fases de creación y de aplicación se hallan } \\
\text { rígidamente separadas. }\end{array}$ & $\begin{array}{l}\text { No se hace referencia a la búsqueda del con- } \\
\text { senso o a la cooperación público-privado en la } \\
\text { ejecución y en el desarrollo de la norma. A su } \\
\text { vez, no se regula - ni parece formar parte del } \\
\text { procedimiento- la supervisión o el control de } \\
\text { las decisiones adoptadas. Nos referimos, por } \\
\text { ejemplo, a las autorizaciones provisionales, a } \\
\text { los efectos indeseados o no previstos de una } \\
\text { evaluación medioambiental, entre otros. }\end{array}$ \\
\hline $\begin{array}{l}\text { Acción } \\
\text { administrativa } \\
\text { interior / } \\
\text { exterior }\end{array}$ & $\begin{array}{l}\text { La legislación de procedimiento mira «hacia } \\
\text { adentro». }\end{array}$ & $\begin{array}{l}\text { Descuida las relaciones interadministrativas en } \\
\text { el plano europeo e internacional. }\end{array}$ \\
\hline $\begin{array}{l}\text { Canales de } \\
\text { comunicación } \\
\text { administración - } \\
\text { ciudadano }\end{array}$ & $\begin{array}{l}\text { La comunicación entre la administración y el } \\
\text { ciudadano se encuentra definida en términos } \\
\text { muy estrechos. La posición de los interesados } \\
\text { y de sus derechos e intereses —amparada } \\
\text { por la seguridad jurídica, de un lado, y la de la } \\
\text { administración, defensora en exclusiva de los } \\
\text { intereses generales, de otro- está definida } \\
\text { de un modo rígido y distante. } \\
\text { En consecuencia, la instrucción del procedi- } \\
\text { miento se realiza de oficio, con un carácter un } \\
\text { tanto paternalista. }\end{array}$ & $\begin{array}{l}\text { No se regula la instrucción practicada por el } \\
\text { sujeto privado, como sucede, por ejemplo, en } \\
\text { el ámbito del medio ambiente. }\end{array}$ \\
\hline $\begin{array}{l}\text { División de } \\
\text { poderes }\end{array}$ & $\begin{array}{l}\text { Comprensión del principio de separación de } \\
\text { poderes como sinónimo de funciones rivales. } \\
\text { Desde la estrecha comprensión tradicional } \\
\text { del principio de división de poderes, el eje- } \\
\text { cutivo - un término que en tantos sistemas } \\
\text { jurídicos sirve para designar al gobierno y a } \\
\text { la administración- se limita a «ejecutar» y a } \\
\text { "administrar», y, en consecuencia, no formula } \\
\text { políticas públicas. Como se trata tan solo de } \\
\text { eso, el procedimiento adquiere una estruc- } \\
\text { tura a imagen y semejanza del proceso, bien } \\
\text { sea con la rúbrica estadounidense del due } \\
\text { process, de la británica natural justice o de la } \\
\text { francesa de los «derechos de defensa». }\end{array}$ & $\begin{array}{l}\text { Las tres funciones son complementarias y alia- } \\
\text { das: las nuevas formas de dirección y gober- } \\
\text { nanza se alejan de ese reduccionismo y recla- } \\
\text { man una comprensión del procedimiento que } \\
\text { no responda a una estructura procesal para } \\
\text { abarcar el ciclo completo de la política pública. }\end{array}$ \\
\hline
\end{tabular}

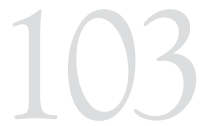

TRES

GENERACIONES

DEL

PROCEDIMIENTO

ADMINISTRATIVO

\section{THREE}

GENERATIONS OF ADMINISTRATIVE PROCEDURE 


\begin{tabular}{|c|c|c|}
\hline & $\begin{array}{l}\text { Notas características del procedimiento } \\
\text { administrativo tradicional }\end{array}$ & $\begin{array}{l}\text { Algunos ejemplos de los } \\
\text { déficits de la legislación de procedimiento } \\
\text { administrativo tradicional }\end{array}$ \\
\hline $\begin{array}{l}\text { Vertiente } \\
\text { defensiva / } \\
\text { activa }\end{array}$ & $\begin{array}{l}\text { El procedimiento presenta un carácter ne- } \\
\text { gativo o defensivo frente a la arbitrariedad y } \\
\text { al abuso de poder de la administración. Por } \\
\text { ello, el procedimiento decisorio pretende } \\
\text { garantizar: } \\
\text { - que las decisiones sean imparciales; } \\
\text { - que sean adoptadas por el órgano com- } \\
\text { petente; } \\
\text { - que se respeten los derechos de los ciuda- } \\
\text { danos. } \\
\text { El procedimiento opera como un mecanismo } \\
\text { de control del poder. }\end{array}$ & $\begin{array}{l}\text { El procedimiento administrativo en positivo, } \\
\text { como instrumento que garantice un correcto y } \\
\text { eficaz ejercicio de la discrecionalidad: } \\
\text { - que las decisiones discrecionales sean razo- } \\
\text { nables y eficaces; } \\
\text { - que se condicionen y enmarquen dentro de } \\
\text { una sólida participación y transparencia; } \\
\text { - que ponderen todos los bienes, derechos e } \\
\text { intereses en presencia. } \\
\text { El procedimiento representa un instrumento } \\
\text { de dirección del poder. }\end{array}$ \\
\hline $\begin{array}{l}\text { Rigidez / } \\
\text { flexibilidad } \\
\text { de los } \\
\text { elementos del } \\
\text { procedimiento }\end{array}$ & $\begin{array}{l}\text { Los procedimientos son «duros» y rígidos. } \\
\text { Se establecen requisitos muy poco flexibles } \\
\text { sobre: } \\
\text { - el alcance de la participación y el momento } \\
\text { en que se produce; } \\
\text { - los canales de participación y la forma de } \\
\text { intercambio de información; } \\
\text { - el modo y la forma en que ha de tomarse } \\
\text { la decisión. }\end{array}$ & $\begin{array}{l}\text { Resultan escasos los requisitos procedimenta- } \\
\text { les de carácter «blando» y flexible. } \\
\text { Esto ocurre cuando se busca una: } \\
\text { - comunicación abierta; } \\
\text { - participación fluida; } \\
\text { - deliberación basada en la búsqueda del } \\
\text { consenso. }\end{array}$ \\
\hline
\end{tabular}

*Se toma como ejemplo la Ley Española de Procedimiento Administrativo (ley 30/1992 de 26 de noviembre de 1992, de Régimen Jurídico de las Administraciones Públicas y del Procedimiento Administrativo Común). 


\section{Cuadro 2 \\ Modelo de administración que subyace a la legislación de procedimiento administrativo tradicional}

\section{Introducción}

\begin{tabular}{|c|c|c|}
\hline & $\begin{array}{l}\text { Modelo de administración de la } \\
\text { legislación tradicional de procedimiento } \\
\text { administrativo }\end{array}$ & $\begin{array}{l}\text { Algunos ejemplos de modelos de } \\
\text { administración ignoradas en la legislación } \\
\text { tradicional de procedimiento administrativo }\end{array}$ \\
\hline $\begin{array}{l}\text { Modelo básico } \\
\text { de actuación } \\
\text { administrativa }\end{array}$ & $\begin{array}{l}\text { La administración característica de la LPA es } \\
\text { la propia de la actividad administrativa de } \\
\text { policía (orden y seguridad públicas), o, más } \\
\text { ampliamente, la de una administración que } \\
\text { actúa con imperium. }\end{array}$ & $\begin{array}{l}\text { Otras formas y modalidades de administración } \\
\text { son ignoradas: por ejemplo, la administración } \\
\text { que garantiza la prestación en el ámbito de la } \\
\text { autorregulación regulada; la administración } \\
\text { que coopera con los sujetos privados; la ad- } \\
\text { ministración que trabaja en común con otras } \\
\text { administraciones en el espacio europeo e in- } \\
\text { ternacional; la administración prestacional; la } \\
\text { administración mediadora; etcétera. }\end{array}$ \\
\hline $\begin{array}{l}\text { Estructura de la } \\
\text { administración }\end{array}$ & $\begin{array}{l}\text { Es una administración jerárquica, cerrada y } \\
\text { piramidal. } \\
\text { Está diseñada para transmitir órdenes e infor- } \\
\text { mación de arriba hacia abajo. }\end{array}$ & $\begin{array}{l}\text { No contempla la administración en red, la cual } \\
\text { coopera horizontal y verticalmente con otras } \\
\text { Administraciones, ni tampoco los organismos } \\
\text { reguladores de los sectores regulados, entre } \\
\text { otros. }\end{array}$ \\
\hline $\begin{array}{l}\text { Técnicas } \\
\text { coercitivas }\end{array}$ & $\begin{array}{l}\text { La legislación de procedimiento concibe a la } \\
\text { administración como una organización que } \\
\text { dicta resoluciones unilaterales y obligatorias, } \\
\text { acompañadas de técnicas coercitivas. }\end{array}$ & $\begin{array}{l}\text { No tienen espacio en la legislación general del } \\
\text { procedimiento: la administración que informa, } \\
\text { la administración que elabora instrumentos de } \\
\text { Derecho blando, la administración que realiza } \\
\text { actividades materiales, entre otras. }\end{array}$ \\
\hline $\begin{array}{l}\text { Organización } \\
\text { administrativas e } \\
\text { información }\end{array}$ & $\begin{array}{l}\text { El flujo de información dentro de la estruc- } \\
\text { tura interna de la administración carece de } \\
\text { interés para la ley. } \\
\text { Las técnicas de colaboración que se siguen } \\
\text { en los procedimientos que se utilizan en el } \\
\text { marco del método tradicional - por ejemplo, } \\
\text { la evacuación de informes de una administra- } \\
\text { ción a otra en los procedimientos de elabo- } \\
\text { ración del planeamiento territorial- resultan } \\
\text { pobres e insuficientes en muchos casos. }\end{array}$ & $\begin{array}{l}\text { Por ejemplo, la obtención, el procesamiento y } \\
\text { el intercambio de información que requiere la } \\
\text { administración en el marco de la autorregula- } \\
\text { ción regulada }-\mathrm{y} \text {, más aún, de las administra- } \\
\text { ciones del espacio comunitario- no es objeto } \\
\text { de atención. }\end{array}$ \\
\hline $\begin{array}{l}\text { Participación } \\
\text { y colaboración } \\
\text { inter- } \\
\text { administrativas }\end{array}$ & $\begin{array}{l}\text { La participación de otros órganos u admi- } \\
\text { nistraciones en el curso del procedimiento } \\
\text { clásico ocupa un lugar secundario. El proce- } \\
\text { dimiento no está concebido como un instru- } \\
\text { mento de colaboración interadministrativa: } \\
\text { se trata de una administración encerrada en } \\
\text { sí misma. }\end{array}$ & $\begin{array}{l}\text { En consecuencia, quedan fuera de la legisla- } \\
\text { ción tradicional, por ejemplo, la administra- } \\
\text { ción «compuesta» o conjunto de adminis- } \\
\text { traciones que actúan en conjunto dentro del } \\
\text { espacio europeo, y, más ampliamente, todos } \\
\text { los supuestos en los que la colaboración no } \\
\text { se basa en un encuentro puntual ni en una } \\
\text { relación jerárquica, o en aquellos donde no } \\
\text { se asienta sobre las premisas de una posición } \\
\text { fragmentada o sectorial. }\end{array}$ \\
\hline $\begin{array}{l}\text { Administración } \\
\text { interna / exterior }\end{array}$ & $\begin{array}{l}\text { Es una administración «estado-céntrica», que } \\
\text { no opera más allá de las fronteras nacionales. }\end{array}$ & $\begin{array}{l}\text { No contempla a la administración nacional en } \\
\text { su condición de administración comunitaria, } \\
\text { menos aún en la acción administrativa inter- } \\
\text { nacional. }\end{array}$ \\
\hline
\end{tabular}

Fuente: elaboración propia

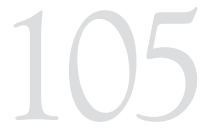

TRES

GENERACIONES

DEL

PROCEDIMIENTO

ADMINISTRATIVO

\section{THREE}

GENERATIONS OF ADMINISTRATIVE PROCEDURE 


\section{Cuadro 3 \\ De la regulación tradicional a la gobernanza}

\begin{tabular}{|c|c|c|}
\hline & $\begin{array}{l}\text { Modelo clásico } \\
\text { de regulacion }\end{array}$ & $\begin{array}{l}\text { Nuevas formas } \\
\text { de dirección y gobernanza }\end{array}$ \\
\hline $\begin{array}{l}\text { Naturaleza del } \\
\text { Derecho }\end{array}$ & $\begin{array}{l}\text { - Predominio de normas de carácter } \\
\text { material o sustantivo. } \\
\text { - Derecho emanado desde un único } \\
\text { centro. } \\
\text { - Derecho imperativo (prohibiciones y } \\
\text { mandatos). } \\
\text { - Normas abstractas, generales y rígidas. }\end{array}$ & $\begin{array}{l}\text { - Elevado número de normas de procedimiento. } \\
\text { - Derecho emanado de forma descentralizada. } \\
\text { - Normas flexibles y adaptadas al contexto y a las } \\
\text { variables. } \\
\text { - Coordinación descentralizada y en red. } \\
\text { - Autorregulación (Derecho reflexivo). }\end{array}$ \\
\hline $\begin{array}{l}\text { Organización } \\
\text { institucional }\end{array}$ & $\begin{array}{l}\text { Organización jerárquica, piramidal y for- } \\
\text { mal (estructurada de arriba hacia abajo) }\end{array}$ & $\begin{array}{l}\text { Organización horizontal estructurada en forma } \\
\text { de red. }\end{array}$ \\
\hline $\begin{array}{l}\text { Actores funda- } \\
\text { mentales }\end{array}$ & $\begin{array}{l}\text { Estado centralizado, como sujeto prota- } \\
\text { gonista. }\end{array}$ & $\begin{array}{l}\text { - Cooperación entre los múltiples niveles de go- } \\
\text { bierno (local, regional, transnacional, interna- } \\
\text { cional). } \\
\text { - Participación de múltiples agentes públicos y } \\
\text { privados. } \\
\text { - Descentralización y principio de subsidiariedad. }\end{array}$ \\
\hline $\begin{array}{l}\text { Proceso de } \\
\text { creación del } \\
\text { Derecho }\end{array}$ & $\begin{array}{l}\text { - El Derecho es estático y estable, per- } \\
\text { manece «petrificado» hasta su dero- } \\
\text { gación. } \\
\text { - Regulación es dictar órdenes, manda- } \\
\text { tos y prohibiciones. }\end{array}$ & $\begin{array}{l}\text { - El Derecho es un proceso abierto, dinámico, y en } \\
\text { constante adaptación. } \\
\text { - Gobernar es un proceso de aprendizaje y de } \\
\text { innovación. } \\
\text { - Los nuevos modelos están mejor posicionados } \\
\text { para aceptar la incertidumbre y la diversidad, } \\
\text { para ensayar y avanzar de forma repetitiva a la } \\
\text { búsqueda de soluciones eficaces. } \\
\text { - El Derecho tiene por objeto promover prácticas } \\
\text { que permitan la revisión y la mejora constantes. }\end{array}$ \\
\hline $\begin{array}{l}\text { Modos de } \\
\text { acción }\end{array}$ & $\begin{array}{l}\text { - Canales formales de actuación } \\
\text { - Actividad administrativa de policía. }\end{array}$ & - Pluralidad de canales de actuación. \\
\hline $\begin{array}{l}\text { Función de } \\
\text { los agentes } \\
\text { privados }\end{array}$ & $\begin{array}{l}\text { - El individuo es objeto de la regulación. } \\
\text { - El individuo es un sujeto que puede o } \\
\text { no cumplir la norma }\end{array}$ & $\begin{array}{l}\text { - El individuo participa activamente en la produc- } \\
\text { ción normativa. } \\
\text { - Ciudadano activo }\end{array}$ \\
\hline $\begin{array}{l}\text { Coactividad } \\
\text { del Derecho }\end{array}$ & $\begin{array}{l}\text { Derecho «duro» o imperativo, acom- } \\
\text { pañado de técnicas coercitivas }\end{array}$ & $\begin{array}{l}\text { - Derecho indicativo o «blando». } \\
\text { - Cooperación voluntaria }\end{array}$ \\
\hline $\begin{array}{l}\text { Uso del cono- } \\
\text { cimiento y de } \\
\text { la información }\end{array}$ & $\begin{array}{l}\text { - La información que ofrece el ciudada- } \\
\text { no es selectiva por miedo a incurrir en } \\
\text { responsabilidad. }\end{array}$ & $\begin{array}{l}\text { - La información es compartida y el flujo perma- } \\
\text { nente. }\end{array}$ \\
\hline $\begin{array}{l}\text { Marco procedi- } \\
\text { mental }\end{array}$ & $\begin{array}{l}\text { - El procedimiento tiene carácter defen- } \\
\text { sivo y se centra en el resultado final. El } \\
\text { control se produce ex post. }\end{array}$ & $\begin{array}{l}\text { - El procedimiento se centra en el proceso mismo. } \\
\text { El control se produce ex ante. }\end{array}$ \\
\hline
\end{tabular}

Fuente: Orly Lobel (2004) y elaboración propia 


\section{Cuadro 4}

\section{Tres generaciones de procedimiento}

\begin{tabular}{|c|c|c|c|}
\hline $\begin{array}{l}\text { Procedimiento } \\
\text { administrativo }\end{array}$ & $\begin{array}{c}\text { Modelo de } \\
\text { procedimiento }\end{array}$ & $\begin{array}{c}\text { Modelo de } \\
\text { administración }\end{array}$ & Modelo de regulación \\
\hline $\begin{array}{l}\text { Primera generación } \\
\text { Procedimiento clásico } \\
\text { dictado de actos admi- } \\
\text { nistrativos }\end{array}$ & Modelo «judicial» & $\begin{array}{l}\text { Administración jerár- } \\
\text { quica y piramidal. }\end{array}$ & $\begin{array}{l}\text { Tradicional: command and con- } \\
\text { trol regulation (actividad admi- } \\
\text { nistrativa de policía). }\end{array}$ \\
\hline $\begin{array}{l}\text { Segunda generación: } \\
\text { Procedimiento clásico: } \\
\text { elaboración de regla- } \\
\text { mentos }\end{array}$ & Modelo «legislativo» & $\begin{array}{l}\text { Administración jerár- } \\
\text { quica y piramidal. } \\
\text { La administración se } \\
\text { limita a ejecutar o «ad- } \\
\text { ministrar», y no formu- } \\
\text { la políticas públicas. }\end{array}$ & $\begin{array}{l}\text { Tradicional: command and con- } \\
\text { trol regulation (actividad admi- } \\
\text { nistrativa de policía). } \\
\text { - Normas basadas en el man- } \\
\text { dato y la prohibición. } \\
\text { - Normas emanadas desde } \\
\text { arriba. } \\
\text { - Administración que actúa } \\
\text { imperativamente y con técni- } \\
\text { cas coercitivas. }\end{array}$ \\
\hline $\begin{array}{l}\text { Tercera generación } \\
\text { Procedimiento } \\
\text { moderno: instrumento } \\
\text { que acompaña el ciclo } \\
\text { completo de la política } \\
\text { pública }\end{array}$ & $\begin{array}{l}\text { Modelo «adminis- } \\
\text { trativo» }\end{array}$ & $\begin{array}{l}\text { Administración coope- } \\
\text { rativa o en red. } \\
\text { La administración no } \\
\text { solo aplica o ejecuta, } \\
\text { sino que formula polí- } \\
\text { ticas públicas. }\end{array}$ & $\begin{array}{l}\text { Nuevas formas de dirección, } \\
\text { regulación y gobernanza: } \\
\text { - Cooperación público- } \\
\text { privada. } \\
\text { - Cooperación interadminis- } \\
\text { trativa (horizontal y vertical). }\end{array}$ \\
\hline
\end{tabular}

TRES

GENERACIONES

DEL

PROCEDIMIENTO

ADMINISTRATIVO

THREE

GENERATIONS OF

ADMINISTRATIVE

PROCEDURE

Fuente: elaboración propia 


\section{Cuadro 5 \\ Características generales de las tres generaciones de procedimiento}

Primera generación de procedi-
mientos administrativos
Legislación tradicional de procedi-
miento administrativo
(Por ejemplo, Ley Española de
Procedimiento Administrativo
de 1889)

Modelo judicial (actos administrativos puramente aplicativos)

El procedimiento es una secuencia de actos de autoridad orientada al dictado de una resolución singular.

Rígida separación entre la creación del Derecho y la aplicación al caso.

Procedimiento como control de la discrecionalidad administrativa

Procedimiento decisorio (actos administrativos)

Aplicación de la Ley Material

Instrumento para la correcta aplicación del Derecho material (acto administrativo singular)

\footnotetext{
El procedimiento no se preocupa de la aplicación más allá de la ejecución forzosa.
}

Obtención de la información: principio de instrucción de oficio
Segunda generación de procedimientos administrativos Legislación tradicional de elaboración de disposiciones reglamentarias (Legislación de las décadas de los cincuenta y sesenta)

Modelo legislativo (reglamentos ejecutivos tradicionales)

El procedimiento tiene por objeto elaborar una norma infralegal.

Procedimiento decisorio (normas reglamentarias)

\section{Desarrollo normativo}

Instrumento para dictar una norma de desarrollo (reglamento ejecutivo) o para la aprobación de un plan territorial o urbanístico.

La aplicación de la norma queda fuera del procedimiento, más allá de las situaciones conflictivas.

Obtención de la información: información pública

\section{Tercera generación de procedi-} mientos administrativos Normativa sectorial (por ejemplo, EE.UU., U.E.):

Medio ambiente Política social Autorregulación

Gobernanza internacional y colaboración público-privado

Modelo administrativo (nuevas formas de regulación y gobernanza)

El procedimiento acompaña el ciclo completo de la política pública. A su vez, se extiende a la formulación de las políticas públicas y sus prioridades, así como también al desarrollo y diseño, y su aplicación efectiva.

Mayor integración entre las distintas fases del proceso legal: normación, desarrollo, aplicación, ejecución forzosa, resolución de conflictos, etcétera.

Procedimiento como dirección de la discrecionalidad administrativa

- Procedimiento decisorio

- Procedimiento no decisorio: cubre actuaciones que no están orientadas a una situación concreta (procedimientos de control, de intercambio de información y otros).

Creación y aplicación del Derecho Instrumento para hallar la mejor solución posible no predeterminada por la Ley Material

(disolución de las fases «creación del Derecho - aplicación»)

La aplicación forma parte esencial del procedimiento y acompaña toda la vida de la resolución (incluye el control y la supervisión).

Obtención de la información: cooperación público-privada y cooperación interadministrativa

Fuente: elaboración propia 